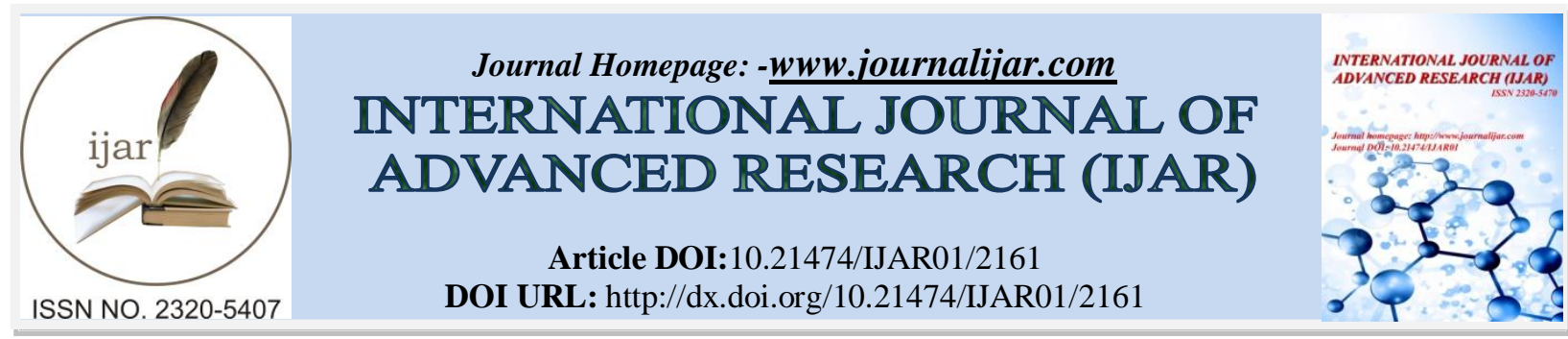

RESEARCH ARTICLE

\title{
SAUDI WOMEN'S OBSTACLES IN USING CONTRACEPTION AND ATTITUDE OF SAUDI MALE IN TAIF REGION, SAUDI ARABIA.
}

\section{Dr. Farzana Rizwan Arain ${ }^{1}$, Dr. Nisreen Aref al-bizrah ${ }^{2}$, Dr. Rehab Ismail ${ }^{3}$ and Dr. Tagreed Ismail ${ }^{3}$.}

1. Mcps, fcps Associate professor,Taif medical collage.KSA.

2. Assistant professor, Taif medical college. KSA.

3. House officer King Abdul-Aziz specialists' hospital Taif, KSA.

\section{Manuscript Info}

(.........................

Manuscript History

Received: 26 September 2016

Final Accepted: 29 October 2016

Published: November 2016

Key words:-

Contraceptive. Reproductive health, family planning, Saudi Arabia, husband, women

\section{Abstract}

Background: The use and avoidance of contraceptive is adopted by individuals and couples on the basis of existing knowledge, attitude towards family planning practices and social and cultural norms. The contraceptive prevalence rate in Saudi Arabia is comparatively low compared to other developed countries. Similar to many Asian countries, topics related to sexuality remained as taboo and obstacles in utilizing of reproductive health services had not been explored extensively among the Saudi population. Therefore the study was conducted to identify contraceptive prevalence, obstacles to use contraceptives and reasons/ methods of contraception opposed by husband.

Methods: A descriptive cross-sectional study was conducted in Obstetrics and Gynecology outpatient clinic in King Abdul Aziz Hospital, Taif from August to October, 2015. The study enrolled married women of reproductive age (18 to 49 years) living with spouse and having at least one child after informed consent. All participants completed a questionnaire inquiring acceptability of contraceptive use, use of contraceptives, perceived barriers in using contraceptives and husband attitude towards contraception. The data was analyzed using SPSS 21.0 statistical software (IBM SPSS Inc., Chicago, IL, USA).

Results: The study participants perceived fear of side effects (55.7\%), followed by accessibility (31.19\%) and husband refusal (14.37\%) as most important obstacles for contraceptive use. Hindrance from family members $(10.4 \%)$ and religious beliefs $(3.97 \%)$ were not identified as important obstacles in using contraceptives. Among one hundred and ninety one women who reflected husband refusal as obstacle for contraceptive use perceived concerns for side effects of contraceptive use for wife $(45.55 \%)$, desire for more children $(30.89 \%)$ and religious aspects $(9.42 \%)$ were the most cited reasons of husband refusal.

Conclusion and Recommendation: The study concluded that married women of reproductive age group perceived fear of side effects, accessibility and husband refusal as most important obstacles 
for contraceptive use. Thus it is highly recommended to educate the health care professionals and use of mass communication so that misconception and lack of reliable and authentic information prevailing related to side effects of contraceptive use could be addressed.

Copy Right, IJAR, 2016,. All rights reserved.

\section{Introduction:-}

Contraception prevents pregnancy by interfering with the normal process of ovulation, fertilization or implantation (Al-Turki, 2011). Contraceptive use to regulate pregnancies and birth spacing is a norm in Western world but it is a significant public health concern for women in developing countries. Darroch et al. (2011) has reported that in developing countries an estimate of 818 million sexually active women of reproductive age want to avoid child bearing for at least two years and among those more than $17 \%$ are not using any contraceptive methods. The prevalence of contraceptive use is considered by World Health Organization (WHO) as an important indicator of women's health status and empowerment in that society (Bernstein \& Edouard, 2007).

The use of contraceptive is adopted by individuals and couples on the basis of existing knowledge and attitude towards family planning practices. A variety of contraceptive methods are available including both traditional (i.e. withdrawal and period abstinence) and modern i.e. male and female condoms, spermicides, pills, injectable, intra uterine devices, implants, and male and female sterilization (Mansour et al. 2010). In many Asian countries, topics related to sexuality remained as taboo and utilization of reproductive health services has been influenced by cultural, socioeconomic, religious and physical norms (Regmi et al. 2010).

Saudi Arabia is the second most populated state in the Arab world after Algeria. A distinct feature of the Saudi Arabian population is the desire for large families (Farrag et al. 1983). A higher birth and total fertility rate compared to other developed countries have been reported, but decrease in both rates has been observed in last few years (World Population Prospects, 2007). Evidence from the literature suggested that total fertility rate of a country is inversely related to contraceptive use prevalence (Mauldin \& Sinding, 1993). However, there is paucity of evidence related to contraceptive prevalence, barriers perceived by women to use contraceptives and husband attitude towards contraceptive methods. Therefore the study was conducted to identify contraceptive prevalence, obstacles to use contraceptives and reasons/ methods of contraception opposed by husband.

\section{Methods:-}

A descriptive cross-sectional study was conducted in Obstetrics and Gynecology outpatient clinic in King Abdul Aziz Hospital, Taif from August to October, 2015. Married women living with spouse, aged 18 to 49 years and having at least one child were invited to participate in the study through convenience sampling method. Prior to enrollment in the study a written informed consent was obtained from all eligible participants. Participation in this study was voluntary and the study participants had the right to withdraw during any stage of the research or not to respond to any one or more questions. Anonymity and confidentiality of the participant's response was maintained throughout the research project. The study was approved by the Institutional Review Board (IRB) of King Abdul Aziz Hospital.

Data was collected using a structured questionnaire developed after review of literature (Najafi-Sharjabad et al. 2013; Karim et al. 2015). Pilot testing of the Questionnaire was performed and the results of the pilot study were discarded and not used in original study. The final Questionnaire in Arabic language consisted of three parts. The first part of the questionnaire collected socio-demographic information (i.e. age, residence as rural or urban, education, occupation, income and parity). The second part collected information on acceptability of contraceptive use, use of contraceptives and perceived barriers in using contraceptives (i.e. fear of side effects, accessibility, husband refusal, hindrance from family members, cost and religious beliefs). The third part of the questionnaire collected data on husband attitude towards contraception with items as reasons of husband opposition towards contraceptive use and contraceptive methods opposed by husband. The time to complete the questionnaire was approximately 8-10 minutes. 


\section{Data Analysis:-}

Then SPSS 21.0 statistical software (IBM SPSS Inc., Chicago, IL, USA) was used for statistical analyses. The data was entered and validated twice for incorrect entries. Questions with missing responses were excluded from analysis. Descriptive statistics were performed. Quantitative variables (i.e. age and parity) were presented as mean \pm standard deviation, while categorical variables (i.e. residence, education, occupation, income, contraceptive use, obstacles in contraceptive use, husband opposition towards contraceptive use and contraceptive methods opposed by husband) were presented as frequency and percentage.

\section{Results:-}

The questionnairewas distributed to 700 eligible participants. The response rate was around eighty three percent (83.3\%) with five hundred and eighty three participants completed the questionnaire. Among those fifty four questionnaires were incomplete or with missing responses which were excluded. Finally, the data of five hundred and twenty nine $(\mathrm{n}=529)$ was analyzed.

The table 1 gives details of the socio demographic characteristics of the study participants. The mean (SD) age of the respondent was 32.07 (7.75). Majority (88.66\%) of the study participants belonged to urban areas. Predominantly, the participants were house wives $(78.07 \%)$ and more than three quarters $(82.61 \%)$ had education of twelve years or less. Majority $(41.97 \%)$ of the respondents had moderate household income, followed by high income $(35.92 \%)$. The mean (SD) parity of the respondent was $3.00(2.3)$.

Among the participants interviewed four hundred and thirty two (81.66\%) reflected acceptance for contraceptive use but the use of contraceptive since last year was reported by less than half (43.6\%).

Table 1:-Socio Demographic characteristics of the study participants $(n=529)$

\begin{tabular}{|l|l|}
\hline Socio Demographic Characteristics & $\mathrm{n}(\%)$ \\
\hline Age & $32.07 \pm 7.75$ \\
\hline Residence & \\
\hline Urban & $469(88.66)$ \\
\hline Rural & $60(11.44)$ \\
\hline Education & $302(57.09)$ \\
\hline$\leq 8$ years & $135(25.52)$ \\
\hline $9-12$ years & $92(17.39)$ \\
\hline$>12$ years & \\
\hline Occupation & $413(78.07)$ \\
\hline House Wife & $116(21.93)$ \\
\hline Working women & \\
\hline Income & $117(22.11)$ \\
\hline Low & $222(41.97)$ \\
\hline Moderate & $190(35.92)$ \\
\hline High & $3.00 \pm 2.3$ \\
\hline Parity & \\
\hline Acceptance to Contraceptive use & $432(81.66)$ \\
\hline Yes & $97(18.44)$ \\
\hline No & \\
\hline Use of Contraceptives & $231(43.67)$ \\
\hline Users & $298(56.33)$ \\
\hline Non Users & \\
\hline
\end{tabular}

The study participants perceived fear of side effects (55.7\%), followed by accessibility $(31.19 \%)$ and husband refusal $(14.37 \%)$ as most important obstacles for contraceptive use. Hindrance from family members (10.4\%) and religious beliefs (3.97\%) were not identified as important obstacles in using contraceptives (Table 2). 
Table 2:-Study participants perception about obstacles in using contraceptives $(\mathrm{n}=529)$

\begin{tabular}{|c|c|}
\hline Obstacles in use of Contraceptives & $\mathrm{n}(\%)$ \\
\hline \multicolumn{2}{|l|}{ Fear of side effects } \\
\hline Yes & $294(55.57)$ \\
\hline No & $104(19.65)$ \\
\hline Don't Know & $131(24.76)$ \\
\hline \multicolumn{2}{|c|}{ Accessibility (distance from the service center) } \\
\hline Yes & $165(31.19)$ \\
\hline No & $164(31)$ \\
\hline Sometimes & $200(37.81)$ \\
\hline \multicolumn{2}{|l|}{ Husbands refusal } \\
\hline Yes & $76(14.37)$ \\
\hline No & $338(63.89)$ \\
\hline Sometimes & $115(21.74)$ \\
\hline \multicolumn{2}{|c|}{ Hindrance from family members (self and spouse) } \\
\hline Yes & $55(10.40)$ \\
\hline No & $441(83.36)$ \\
\hline Sometimes & $33(6.24)$ \\
\hline \multicolumn{2}{|l|}{ Cost } \\
\hline Yes & $70(13.23)$ \\
\hline No & $459(86.77)$ \\
\hline \multicolumn{2}{|l|}{ Religious Beliefs } \\
\hline Yes & $21(3.97)$ \\
\hline No & $397(75.05)$ \\
\hline Don't Know & $111(20.98)$ \\
\hline
\end{tabular}

Among one hundred and ninety one women who reflected husband refusal as obstacle for contraceptive use perceived concerns for side effects of contraceptive use for wife (45.55\%), desire for more children $(30.89 \%)$ and religious aspects $(9.42 \%)$ were the most important reasons of husband refusal. The respondents were of the view that slightly more than fifty percent $(51.3 \%)$ husbands oppose modern contraceptive methods. Among the modern contraceptive methods male condoms (46.88\%), IUD (19.79\%) and OCPs (15.63\%) were most opposed by husbands. While in traditional contraceptive methods, participants reported that more than three fifth $(63.16 \%)$ of husbands opposes withdrawal as contraceptive method (Table 3).

Table 3:-Husband attitude towards contraceptive use $(\mathrm{N}=191)$

\begin{tabular}{|l|l|}
\hline Husband attitude towards contraceptive use & $\mathrm{n}(\%)$ \\
\hline Husband opposition towards contraceptive use & \\
\hline Affect marital life & $8(4.19)$ \\
\hline Desire for more children & $59(30.89)$ \\
\hline Concerned about side effects of contraceptive use for wife & $87(45.55)$ \\
\hline Religious aspects & $18(9.42)$ \\
\hline No reason identified & $19(9.95)$ \\
\hline Contraceptive methods opposed by husband & \\
\hline Traditional & $95(49.7)$ \\
\hline Withdrawal & $60(63.16)$ \\
\hline Period abstinence & $35(36.84)$ \\
\hline Modern & $96(51.3)$ \\
\hline Male condoms & $45(46.88)$ \\
\hline Oral contraceptive pills (OCPs) & $15(15.63)$ \\
\hline Intrauterine device (IUD) & $19(19.79)$ \\
\hline Tubal ligation & $7(7.29)$ \\
\hline Transdermal patches & $5(5.21)$ \\
\hline Hormonal injection & $5(5.21)$ \\
\hline
\end{tabular}




\section{Discussion:-}

The results of the present study conducted among the married women of reproductive age residing in Taif, Saudi Arabia reported the prevalence of contraceptive use less than fifty percent. Importantly, the study identified that these women perceived fear of side effects, accessibility and husband refusal as most important obstacles for contraceptive use. The hindrance from family members and religious belief were not sought as important obstacle in using contraceptives. The study also reported that prominent reasons for husband refusals were desire for more children and concerns related to side effects of contraceptive use. Importantly, husband of more than half of these married women of Taif opposes the use of modern contraceptive methods.

The present study reported the contraceptive use of $43.67 \%$ among married women of reproductive age in Taif. The reported prevalence of contraceptive use (World Contraceptive Use, 2007) was found far lower than the global rates $(63.1 \%)$ as well as in developed countries $(67.4 \%)$ and other countries of Middle East i.e. Syria (58.3\%) and Bahrain (61.8\%). The results of the recent Demographic Health Survey (DHS) reported a variable contraceptive prevalence rate in different countries of the region; Azerbaijan (14\%), Armenia (20\%), Pakistan (22\%), Philippine (34\%), Cambodia (35\%), Jordan (42\%), Bangladesh (49\%) and (49\%) in India (Westoff, 2012). The result of the study is consistent with the previously conducted study in Saudi Arabia which reported the contraceptive prevalence rate as $40 \%$ (Al Sheeha, 2010).

Though, since last decade there has been a change in the socio demographic pattern of Saudi Arabia with women getting more empowerment, employment opportunities and higher education but still not much have changed in terms of the contraceptive practices. The study participants perceived fear of side effects $(55.7 \%)$, followed by accessibility (31.19\%) and husband refusal (14.37\%) as most important obstacles for contraceptive use. The findings of the study is consistent with the previous study conducted at the Primary care clinic of King Khalid University Hospital, Riyadh, Saudi Arabia where medical side effects were perceived as the main obstacle in contraceptive use by majority (73.3\%) of women. Moreover, less than fourteen percent perceived religious beliefs and accessibility as barriers for contraceptive use (Karim et al. 2015). Fear of side effects of contraceptive use and health concerns has also been documented as common reason for not using contraceptive in other studies from Asia (Sedgh et al. 2007; Sajid\& Malik, 2010). Moreover, Saudi women have limited mobility and accessibility to public places because of the cultural norms, thus they might find at times difficult to access reproductive health service (Al-Riyami et al. 2004). An important finding of the study is married women enrolled in the study perceive religious belief as least important obstacle in using contraceptive. This is significantly lower than the reported obstacle in previous study conducted in the kingdom (Karim et al. 2015) where less than fourteen percent perceived religious beliefs and accessibility as barriers for contraceptive use. The finding reflects that the married women believe that contraceptive practices and birth spacing is permissible in Islam. The results were also in accordance with the study conducted in Jordan, where around three quarters of women believe that family planning practices are allowed in Islam (Gharaibeh et al. 2011).

The results of the present study documented husband refusal as most important obstacles for contraceptive use with prominent reasons for husband refusals were desire for more children and concerns related to side effects of contraceptive use. The findings are similar to previous study conducted among Turkish married women who also reported husband opposition as main reason for not using contraceptives (Sahin, 2003). Another study from Pakistan reported that majority (67.5\%) of husbands decides on use of contraceptives and desired number of children (Shah and Ahman, 2009). A recent study from Jordan reported that around twenty two percent of the women reported husband refusal to use contraceptive (Gharaibeh et al. 2011).

\section{Policy Implication:-}

The findings of the present study conducted among the Saudi married women residing in Taif region are significant in terms of policy implications. The findings will help the health authorities to better understand the barriers in contraceptive use and draft future reproductive health policies to increase the contraceptive use and improve information delivery system within the Kingdom. Moreover, healthcare professional responsible for counseling related to reproductive health could be better educated by tailored and customaries training sessions developed considering the social, cultural and religious norms of the society. Importance should be given to update providers with the availability of modern contraceptive methods, side effects associated with it and choice of more suitable contraceptive methods so that married couples could be better counseled in choosing appropriate contraceptive methods and obstacles as well as misconception related to contraceptive use could be overcome. This would be vital 
for improving the reproductive health of women, reducing financial burden on household and improving the quality of life and economy of the country and its residents.

\section{Limitations:-}

The study has few limitations. Firstly, being a cross-sectional survey conducted at single tertiary care setting of Taif region, the findings could not be generalizable. Moreover, only Saudi women who can understand Arabic language were recruited in the study which not be the representative community of the region. Moreover, the participants were recruited through convenience sampling, thus induces the chances of sampling bias. Considering the sensitive nature of the study, there was substantial non-response and missing response which was tried to overcome by using a larger sample size. Importantly, considering the nature of study being quantitative no in depth interviews were conducted to better explore the ideas and concerns related to contraceptive use. Further, the reasons for husband refusal to contraceptive use were inquired from women which itself has its own limitation overestimating and under reporting. Thus, in future a multicenter study using a mixed method approach with recruitment of both husband and wife will be beneficial in more realistic and precise estimate of obstacles to contraceptive use in the Saudi population.

\section{Conclusion:-}

The study concluded that married women of reproductive age group perceived fear of side effects, accessibility and husband refusal as most important obstacles for contraceptive use. It was also identified that prominent reasons for husband refusals were desire for more children and concerns related to side effects of contraceptive use. Importantly, husbands had reluctance to use modern contraceptive methods. Thus it is highly recommended to educate the health care professionals and use of mass communication so that misconception and lack of reliable and authentic information prevailing related to side effects of contraceptive use could be addressed.

\section{References:-}

1. Al Riyami, A., Afifi, M., \& Mabry, R. M. (2004). Women's autonomy, education and employment in oman and their influence on contraceptive use. Reproductive Health Matters, 12(23), 144-154.

2. Al Sheeha, M. (2010). Awareness and use of contraceptives among Saudi Women attending Primary Care. International journal of health sciences, 4(1), 13-20.

3. Al-Turki, H. A. (2011). Contraception: Attitudes and experiences of Saudi arabian women. Health Care for Women International, 32(2), 134-139.

4. Bernstein, S., \& Edouard, L. (2007). Targeting access to reproductive health: Giving contraception more prominence and using indicators to monitor progress. Reproductive Health Matters, 15(29), 186-191.

5. Farrag, O. A., Rahman, M. S., \&Rahman, J. (1983). Attitude towards fertility control in the eastern province of saudiarabia. Saudi Medical Journal, 4(2), 111-116.

6. Gharaibeh, M. K., Oweis, A., Shakhatreh, F. M., \&Froelicher, E. S. (2011). Factors associated with contraceptive use among jordanianmuslim women: Implications for health and social policy. Journal of International Women's Studies, 12(3), 168-184.

7. Karim, S. I., Irfan, F., Al Rowais, N., Al Zahrani, B., Qureshi, R., \& Al Qadrah, B. H. (2015). Emergency contraception: Awareness, attitudes and barriers of saudiarabian women. Pakistan Journal of Medical Sciences, 31(6), 1500-1505.

8. Mansour, D., Inki, P., \&Gemzell-Danielsson, K. (2010). Efficacy of contraceptive methods: A review of the literature. European Journal of Contraception and Reproductive Health Care, 15(1), 4-16.

9. Mauldin, W. P., \& Sinding, S. W. (1993). Review of existing family planning policies and programs: lessons learned.

10. Najafi-Sharjabad, F., Zainiyah Syed Yahya, S., Abdul Rahman, H., HanafiahJuni, M., \& Abdul Manaf, R. (2013). Barriers of modern contraceptive practices among asian women: A mini literature review. Global Journal of Health Science, 5(5), 181-192.

11. Regmi, P. R., Simkhada, P., \& Van Teijlingen, E. R. (2008). Sexual and reproductive health status among young people in nepal: Opportunities and barriers for sexual health education and services utilization. Kathmandu University Medical Journal, 6(22), 248-256.

12. Sahin, H. A., \& Sahin, H. G. (2003). Reasons for not using family planning methods in Eastern Turkey. European Journal of Contraception and Reproductive Healthcare, 8(1), 11-16.

13. Sajid, A., \& Malik, S. (2010). Knowledge, Attitude and Practice of Contraception Among Multiparous Women at Lady Aitchison Hospital, Lahore. Annals of King Edward Medical University, 16(4), 266-269. 
14. Sedgh, G., Hussain, R., Bankole, A., \& Singh, S. (2007). Women with an unmet need for contraception in developing countries and their reasons for not using a method. Occasional report, 37, 5-40.

15. Shah, I., \&Åhman, E. (2009). Unsafe abortion: Global and regional incidence, trends, consequences, and challenges. Journal of Obstetrics and Gynaecology Canada, 31(12), 1149-1158.

16. Westoff, C. F. (2012). Unmet Need for Modern Contraceptive Methods. DHS Analytical Studies No. 28. Calverton, Maryland, USA: ICF International.

17. World Contraceptive Use (2007). United Nations, Department of Economic and Social Affairs, Population Division.

18. World Population Prospects (2007). International, 2006 revision: Highlights. United Nations, New York. 